dungen und damit eine Strukturänderung wenigstens in kleineren Bereichen des Makromoleküls mit sich.

Auch die Variation des Reaktionsmilieus oder Substrats bewirkte eine Verschiebung der Anomaliebereiche. Wäre nur die Struktur des freien Enzyms allein für die Anomalien wichtig, so hätte man in obigem Fall gleiche $\vartheta$-Werte zu erwarten. Da dies aber nicht zutrifft, scheint die Struktur des Enzyms im Michaelis-Komplex maßgebend zu sein. Nach den bisherigen Befunden geht nämlich eine Er- höhung der $K_{\mathrm{m}}$ durch Zusätze mit einer Verschiebung von $\vartheta_{\mathrm{A}}$ nach tieferen Temperaturen konform und umgekehrt. Man kann dies so verstehen: Je instabiler der ES-Komplex wird, desto leichter ist es auch, durch Temperaturerhöhung seine Struktur zu verändern und damit Wechsel des Reaktionsablaufes hervorzurufen.

Herrn Prof. F. Patat danke ich für sein reges Interesse an dieser Arbeit, der Deutschen For.

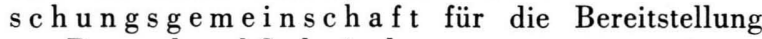
von Personal- und Sachmitteln.

\title{
Fr-Spezifische RNA in Escherichia coli während der Phagenvermehrung
}

\author{
Peter Knolle * \\ (Z. Naturforschg. 22 b, 1118-1129 [1967] ; eingegangen am 3. Oktober 1966)
}

\begin{abstract}
The appearance of fr-specific RNA components was followed in two strains of $E$. coli $\mathrm{K} 12$ growing in supplemented minimal medium. Under these conditions the eclipse period was $25 \mathrm{~min}$. and the latent period 50 minutes. Using pulses with ${ }^{14} \mathrm{C}$-uracil for $5 \mathrm{~min}$ followed by chases for 10 min, labelled RNase-resistant components appeared simultaneously with labelled material corresponding to phage RNA. The peak of the RNase-resistant components was found to sediment initially at $6 \mathrm{~s}$. As replication progressed, it sedimented with increasingly higher values, reaching a maximum of $11.5 \mathrm{~s} 80 \mathrm{~min}$ after infection. Properties of this RNase-resistant fraction resemble those expected of partially double-stranded material as it is assumed to be present in "replicative intermediates I and II".
\end{abstract}

Die Besonderheiten der RNA-Synthese in Bakterien, die mit jenen kleinen Bakteriophagen infiziert sind, die eine einsträngige RNA als ihr genetisches Material enthalten, werden seit einigen Jahren eingehend untersucht. Dabei konnte neben der PhagenRNA eine doppelsträngige RNA als „replikatives Intermediärprodukt“ ( $\left.\mathrm{RI}^{* *}\right)$ in Bakterien nachgewiesen werden, die mit $\mathrm{MS}^{1,2}, \mathrm{fr}, \mathrm{M} 12^{4}, \beta^{5}$, $\mathrm{R} 17^{6}$ oder $\mathrm{f} 2{ }^{7}$ infiziert waren.

Eine wesentliche Schwierigkeit bei der Untersuchung des RI bereitet die Tatsache, daß während der Phagenvermehrung die zelleigene RNA-Synthese mehr oder weniger fortgesetzt wird. Diese Schwie-

\footnotetext{
* Diese Arbeit wurde im Max-Planck-Institut für vergleichende Erbbiologie und Erbpathologie begonnen und mit einem Habilitationsstipendium der D e u t s chen For. $\mathrm{sch}$ ung s g e m e in s c h a f t beendet. Jetzige Anschrift des Verfassers: New York University School of Medicine, Department of Biochemistry, 550 First Avenue, New York, NY, USA, 10016.

** Abkürzungen: $\mathrm{CM}=$ Chloramphenicol, $\mathrm{EM}=$ Eingabe multiplizität, $M W=$ Molekulargewicht, $O D=$ optische Dichte, $\mathrm{RI}=$ replikatives Intermediärprodukt, $\mathrm{SRP}=\mathrm{Se}$ rumresistente plaquebildende Einheit, $\mathrm{TCE}=$ Trichloressigsäure, TRIS = Tris (Hydroxymethyl) aminomethan, $\mathrm{YT}=$ Yeast-Tryptone-Medium (17), mRNA $=$ Messenger RNA, rRNA $=$ ribosomale RNA, $t$ RNA $=$ Transfer RNA.

1 C. Weissmann, P. Borst, R. H. Burdon, M. A. Billeter u. S. OсноA, Proc. nat. Acad. Sci. USA 51, 682 [1964].
}

rigkeit konnte dadurch umgangen werden, daß der jeweilige Phagenwirt durch UV-Bestrahlung ${ }^{6,8}$ oder durch Actinomycin D-Behandlung ${ }^{2,9}$ soweit geschädigt wurde, daß dessen RNA-Syntheseaktivität vernachlässigbar gering war. Bei dieser Behandlung wurde allerdings gleichzeitig die Phagensynthese erheblich reduziert. Dadurch mögen die uneinheitlichen physikalischen und biologischen Eigenschaften der beschriebenen phagenspezifischen RNA-Fraktionen bedingt sein.

Aber auch in RNA-Extrakten ungeschädigter, frinfizierter Zellen wurde heterogene, doppelsträngige RNA gefunden, die je nach Aufarbeitungs-

2 R. B. Kelly u. R. L. Sinsheimer, J. molecular Biol. 8, 602 [1964].

3 H. C. Kaerner u. H. Hoffmann-Berling, Z. Naturforschg. 19 b, 593 [1964].

4 J. Amman, H. Delius u. P. H. Hofschneider, J. molecular Biol. 10, 557 [1964].

5 M. Nonoyama u. Y. Ikeda, J. molecular Biol. 9, 763 [1964].

6 M. L. Fenwick, R. L. Erikson u. R. M. Franklin, Science [Washington] 146, 527 [1964].

7 H. F. Lodish u. N. D. Zinder, Science [Washington] 152 , 372 [1966].

8 R. L. Erikson, M. L. Fenwick u. R. M. FrankLin, J. molecular Biol. 10, 519 [1964].

9 R. B. Kelly, J. L. Gould u. R. L. Sinsheimer, J. molecular Biol. 11, 562 [1965]. 
methode bei $8,5 \mathrm{~s}$, bei $11 \mathrm{~s}$ sowie auch bei höheren $\mathrm{s}$-Werten sedimentierte. Aus der $11 \mathrm{~s}$-Fraktion konnte durch wiederholtes Umfällen eine Komponente angereichert werden, die als scharfe Bande, entsprechend $s_{20}=14$ sedimentierte $^{3}$. Wurden RNA-Extrakte aus fr-infizierten Zellen im Sucrosegradienten sedimentiert, so fand sich der Gipfel der RNase-resistenten RNA bei etwa $6-8 \mathrm{~s}^{\mathbf{1 0}, 11}$. Dieser Gipfel schien während der Phagenvermehrung mit uneinheitlichen $s$-Werten zu sedimentieren.

Die vorliegenden Experimente wurden unternommen, um in fr-infizierten (im übrigen physiologisch ungestörten) Zellen die Bildung von phagenspezifischer RNA während der Virusvermehrung zu verfolgen. Damit sollte gleichzeitig eine der Grundlagen für die folgende Arbeit ${ }^{12}$ geschaffen werden, bei der es erforderlich war, die Bildung phagenspezifischer RNA in auxotrophen Bakterienmutanten in Gegenwart und in Abwesenheit benötigter Aminosäuren zu vergleichen.

\section{Materialien und Methoden}

Phagen und Bakterien: Der Phage fr wurde von HoffMAnN-Berling et al. beschrieben ${ }^{13}, 14$. Die Bakterienstämme sind Abkömmlinge von E. coli K12: 3300 , $3300-141$ (leu ${ }^{-} \mathrm{his}^{-} \mathrm{B}_{1}{ }^{-} \mathrm{RC}^{\mathrm{rel}}$ ), $58-161-22$ (met ${ }^{-} \mathrm{his}^{-}$$\left.\mathrm{F}^{+} \mathrm{RC}^{\mathrm{rel}}\right)$. Ihre Herkunft ist an anderer Stelle beschrieben worden ${ }^{11}$.

Medien und Puffer (ausführliche Beschreibung s. 1. c. $\left.{ }^{11}\right)$ :

T-Puffer [g] : $1,5 \mathrm{KCl}, 4,6 \mathrm{NaCl}, 1 \mathrm{NH}_{4} \mathrm{Cl}, 13$ TRIS, $10 \mathrm{KH}_{2} \mathrm{PO}_{4}, 1,75 \mathrm{MgSO}_{4} \cdot 7 \mathrm{H}_{2} \mathrm{O}$ pro $l, p_{\mathrm{H}} 7$. T-Medium: T-Puffer plus $5 \mathrm{ml}$ 40-proz. Glucose- und $10 \mathrm{ml}$ Aminosäurelösung $(2 \mathrm{mg} / \mathrm{ml})$ pro Liter.

PHOT-Puffer und PHOT-Medium: Die Zusammensetzung entspricht T-Puffer und T-Medium, jedoch mit nur $0,667 \mathrm{~g} \mathrm{KH}_{2} \mathrm{PO}_{4}$ pro Liter.

TRIBEM-Puffer: $0,472 \mathrm{~g}$ Bernsteinsäure, $1,212 \mathrm{~g}$ TRIS, $2,46 \mathrm{~g} \mathrm{MgSO}_{4} \cdot 7 \mathrm{H}_{2} \mathrm{O}$ pro Liter.

NACI-Puffer: $8,75 \mathrm{~g} \mathrm{NaCl}, 4,4 \mathrm{~g}$ Natriumcitrat pro $l$, $p_{\mathrm{H}} 7$.

10 ACE-Puffer: 1-m. Ammoniumacetat, $p_{\text {H }} 5$; ACEPuffer: 0,1-m. Ammonniumacetat, $p_{\text {H }}$ 5. Sucrose (5 und 20-proz.) : in ACE-Puffer und 0,1-m. $\mathrm{NaCl}^{11}$.

Wachstum und Aufarbeitung der Zellen bei ${ }^{14} \mathrm{C}$-Uracilmarkierung: Einer in T-Medium bei $37^{\circ}$ exponen-

10 P. Knolle u. F. Kaudewitz, VI. Internat. Congr. Biochem., Abstracts III-37.

11 P. Knolle, Acta Biol. Med. German 18, 21 [1967].

12 P. Knolle, Z. Naturforschg. 22 b, 1130 [1967].

13 H. Hoffmann-Berling, D. A. Marvin u. H. Duerwald, Z. Naturforschg. 18 b, 876 [1963].

14 D. A. Marvin u. H. Hoffmann-Berling, Z. Naturforschg. 18 b, 884, [1963]. tiell wachsenden Kultur $\left(400 \mathrm{ml}\right.$, Titer $\left.3-4 \cdot 10^{8}\right)$ wurde $\mathrm{MgCl}_{2}$ (Endkonz. 0,01-m.) und anschließend $\mathrm{fr}$ (EM 10) zugefügt. Nach 10 min wurde die Kultur auf T-Puffereis gegossen, gewaschen und in T-Medium bei $37^{\circ}$ resuspendiert. ${ }^{14} \mathrm{C}$-Uracil $(2 \mu \mathrm{c})$ wurde für $45 \mathrm{~min}$ zugefügt. Die Zellen wurden abgeschleudert, gewaschen und in $10 \mathrm{ml}$ TRIBEM-Puffer suspendiert. Die RNA wurde nach der von KJeldgaARd und KurLand ${ }^{15}$ angegebenen Methode extrahiert.

Die Sedimentation erfolgte in einem 5-20-proz. linearen Sucrosegradienten (15 Stdn. - 23000 UPM. SW 25 Rotor, Spinco Modell L, ca. $5^{\circ}$ ), der in 0,5 mlPortionen mit Hilfe eines Auslaufgerätes ${ }^{16}$ fraktioniert wurde. Die UV-Absorption $(260 \mathrm{~m} \mu)$ der Fraktionen wurde mit einem Zeiß-Spektrophotometer bestimmt, die ${ }^{14} \mathrm{C}$-Aktivität wurde mit einem Methan-Durchflußzähler (Friesecke \& Hoepfner, Erlangen-Bruck) gemessen. In einigen Fraktionen wurde der Anteil an RNase-resistentem Material bestimmt (in Anlehnung an Weissmann et al., l. c. ${ }^{1}$ ) : 1 Vol. der Fraktion wurde in 9 Vol. einer Lösung mit $0,5 \mu \mathrm{g}$ RNase/ml NACIPuffer verdünnt, 20 min bei Zimmertemperatur bebrütet und mit TCE versetzt (Endkonz. 5-proz.). Das Sediment wurde auf Membranfiltern (Co 5, Membranfiltergesellschaft, Göttingen) gesammelt. Die Radioaktivität wurde im Methan-Durchflußzähler bestimmt.

Wachstum und Aufarbeitung der Zellen bei Doppelmarkierung *: Exponentiell in PHOT-Medium wachsende Zellen wurden mit ${ }^{32} \mathrm{P}(0,2 \mathrm{mc} / 100 \mathrm{ml})$ für $2 \frac{1}{2}$ Generationszeiten markiert. Sie wurden anschließend gewaschen, in PHOT-Medium für eine weitere Generationszeit bebrütet und schließlich mit $1-m . \mathrm{CaCl}_{2}$ $(1 / 1000$ Vol.) versetzt. Eine Kontrollprobe wurde entnommen und fr dem Rest zugefügt (EM 3-5). Weitere Proben wurden zur Untersuchung früher Vermehrungsstadien entnommen, der Rest wurde 32 min nach der Infektion in der Kälte abzentrifugiert, gewaschen und in PHOT-Medium weiterbelüftet. Zur Pulsmarkierung wurden jeweils $50 \mathrm{ml}$-Proben mit $2 \mu \mathrm{c}{ }^{14} \mathrm{C}$-Uracil, und zur "chase"-Markierung 5 min später mit $2 \mathrm{ml}$ einer nichtmarkierten Uracillösung $(2 \mathrm{mg} / \mathrm{ml})$ versetzt; nach $10 \mathrm{~min}$ wurde die Phagenvermehrung mit $\mathrm{Na}$ triumacid angehalten ${ }^{17}$. Die Zellen wurden in PHOTPuffer gewaschen und in $5 \mathrm{ml}$ TRIBEM-Puffer suspendiert.

RNA-Extraktion: Für die doppelmarkierten Zellen wurde eine Abwandlung der Methoden von KJELDGAARD und Kurland ${ }^{15}$ und von $S_{\text {AGIK }}$ et al. ${ }^{18}$ benutzt (vgl. auch l.c. ${ }^{11}$ ). Die in $5 \mathrm{ml}$ TRIBEM suspendierten Zellen wurden in Gegenwart von Lysozym $(10 \mu \mathrm{g} / \mathrm{ml})$ und DNase $(4 \mu \mathrm{g} / \mathrm{ml})$ eingefroren und getaut. Dem Lysat wurde Dodecylsulfat (0,1-proz.) und Bentonit (150 mg)

15 N. O. KJeldgaard u. D. G. Kurland, J. molecular Biol. 6, 341 [1963].

16 P. Knolle u. H. J. Luedke, Acta Biol. Med. German 16, 222 [1966].

* Die Methode ist an anderer Stelle ausführlich beschrieben ${ }^{11}$.

17 P. Knolle, Zbl. Bakteriol. I Orig. 202, 40 [1967].

18 B. P. Sagik, M. H. Green, M. Hayashi u. S. Spiegelman, Biophys. J. 2, 409 [1962]. 
zugefügt. Die Nucleinsäuren wurden mit TRIBEM-gesättigtem Phenol extrahiert (2-mal), mit 1/10 Vol. 10-ACE-Puffer auf $p_{\mathrm{H}} 5$ gebracht und 2-mal mit Äthylalkohol gefällt. Das Sediment wurde schließlich in 0,6 ml ACE-Puffer aufgenommen und eingefroren.

Gradientensedimentation und -fraktionierung: siehe l. c. ${ }^{11,16}$

Analyse der Gradientenfraktionen: Die Nucleinsäuren der Gradientenfraktionen wurden mit 6-proz. TCE gefällt. Das Sediment wurde auf Membranfiltern gesammelt und dessen Radioaktivität im Flüssigkeitsszintillations-Spektrometer bestimmt ${ }^{11}$.

RNase-Behandlung von Gradientenfraktionen *: Alternierende Gradientenfraktionen wurden mit $1 \mathrm{ml}$ RNase A $(6,5 \mu \mathrm{g} / \mathrm{ml}$ NACI-Puffer $)$ versetzt und für 30 min bei $37^{\circ}$ bebrütet. Nach Fällung mit kalter TCE (6-proz.) wurde das Sediment wie vorher beschrieben gesammelt und dessen Radioaktivität bestimmt.

RNase-Behandlung von RNA-Extrakten vor Gradientensedimentation: Der RNA-Extrakt infizierter Zellen (entsprechend $25 \mathrm{ml}$ Zellsuspension) wurde mit RNase A in NACI-Puffer für $30 \mathrm{~min}$ bei $37^{\circ}$ behandelt, gekühlt, mit einem Überschuß von ${ }^{32}$ P-markierter RNA (aus nicht-infizierten Zellen) versetzt und anschließend sofort im Sucrosegradienten sedimentiert.

Auf Grund früherer Ergebnisse ${ }^{11}$ konnten optimale Bedingungen für die Darstellung von doppelsträngiger RNA abgeschätzt werden. Bei jenen Untersuchungen wurden verschiedene Konzentrationen eines entsprechenden RNA-Extraktes infizierter Zellen mit RNase A behandelt und die Menge des verbleibenden TCE-fällbaren Material bestimmt. Mit dem unverdünnten Extrakt (entsprechend $50 \mathrm{ml}$ Zellsuspension) wurde nach $30 \mathrm{~min}$ bei $37^{\circ}$ mit $6,5 \mu \mathrm{g}$ RNase $/ \mathrm{ml}$ noch $20 \%$ TCEfällbares Material gefunden, d.h. doppelt soviel, wie mit 1/5 oder 1/25 verdünnten Proben des Extraktes. Es ist jedoch zu berücksichtigen, daß die Wirkung der RNase auf das ${ }^{14} \mathrm{C}$-markierte Material durch die $\mathrm{Zu}$ gabe eines Überschusses von ${ }^{32} \mathrm{P}$-markierter BakterienRNA sowie durch Zentrifugierung in der Kälte zwar reduziert, aber nicht aufgehoben ist. Wenn also statt 3,3

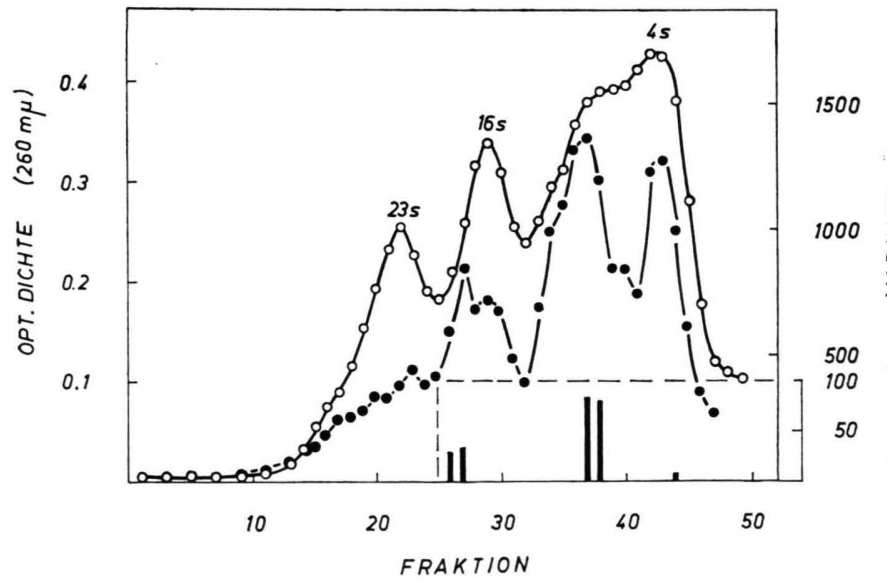

$\mu \mathrm{g}$ (pro $25 \mathrm{ml}$ Zellsuspensionsäquivalent) nur $0,33 \mu \mathrm{g}$ $\mathrm{RNase} / \mathrm{ml}$ zur Behandlung des Extraktes benutzt wurden, dürften die Bedingungen milde sein. Als Kontrollen wurden jedoch auch Behandlungen mit 0,033, 3 und $33 \mu \mathrm{g}$ RNase/ml durchgeführt.

Biologische Analysen: Phagen- und BakterientiterBestimmungen wurden nach den üblichen Methoden mit DIFCO Nutrient Broth Agar durchgeführt ${ }^{19}$. Die Zahl der intrazellulär gereiften Phagen wurde wie an anderer Stelle näher beschrieben bestimmt ${ }^{17}$ : Eine Zellprobe wurde $1 / 100$ in $5 \mathrm{ml}$ PHOT-Puffer (enthaltend $0,01-m$. Natriumacid und $0,1 \mathrm{ml}$ Lysozym $(1 \mathrm{mg} / \mathrm{ml})$, $\left.4^{\circ}\right)$ verdünnt und sofort im Aceton-Trockeneisbad eingefroren. Die Zellen wurden aufgetaut und dabei lysiert. Der Phagentiter des Lysates wurde nach entsprechender Verdünnung bestimmt.

Enzyme und radioaktive Präparate: Pankreas RNase, Pankreas RNase A, DNase und Lysozym waren Produkte von Worthington Enzymes, Freehold, NJ, USA. ${ }^{14}$ C-Uracil (spez. Akt. $40,6 \mathrm{mc} / \mathrm{mMol}$ ) stammte von Radiochemical Centre, Amersham, England, ${ }^{32} \mathrm{P}$ (trägerfreies Orthophosphat) wurde von Fa. Buchler, Braunschweig, bezogen.

\section{Ergebnisse}

\section{Einbau von ${ }^{14} C$-Uracil in RNA-Fraktionen fr-infizierter Zellen}

Im Sedimentationsdiagramm der RNA fr-infizierter Zellen können neben den RNA-Komponenten des Wirtes auch phagenspezifische RNA-Fraktionen nachgewiesen werden ${ }^{11}$. In einem Vorversuch wurden Zellen von Stamm 3300-141 in T-Medium mit fr infiziert und von 10 bis 55 min nach der Infektion mit ${ }^{14} \mathrm{C}$-Uracil versetzt. Das Sedimentationsdiagramm der RNA dieser Zellen ist in Abb. 1 dargestellt. Im Vergleich zu Diagrammen, die mit der RNA nicht-
500

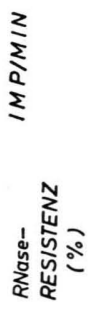

Abb. 1. Einbau von ${ }^{14} \mathrm{C}$-Uracil in RNAFraktionen fr-infizierter Zellen. Fr-infizierte Bakterien (3300-141) wurden von 10 bis 55 min nach der Infektion mit ${ }^{14} \mathrm{C}$-Uracil versetzt. Die RNA wurde extrahiert und im Sucrosegradienten (5-20-proz.) sedimentiert (15 Stdn. - 23000 UPM, Spinco SW 25). Die $O D$ und die ${ }^{14} \mathrm{C}$-Aktivität der Fraktionen wurde bestimmt. Einige Fraktionen wurden auf ihren Gehalt an RNase-resistentem Material untersucht (s. Methoden). 
infizierter Zellen erhalten werden, fällt hier eine zwischen 4 und $16 \mathrm{~s}$ sedimentierende, UV-absorbierende Fraktion auf. In dieser Fraktion findet sich eine erhöhte spezifische ${ }^{14} \mathrm{C}$-Markierung bei etwa $8-10 \mathrm{~s}$. Dieser Bereich zeichnet sich außerdem durch eine größere RNase-Resistenz der ${ }^{14} \mathrm{C}$-Aktivität aus. Eine leichtere Fraktion ist weitgehend RNase-sensitiv, während RNase-resistente Komponenten auch noch in den Bereich höherer $s$-Werte zu reichen scheinen.

RNase-Resistenz ist ein charakteristisches Merkmal eines RNA-Doppelstranges; der $s$-Wert des Gipfels der hier beobachteten Fraktion entspricht aber nicht dem zu erwartenden Wert eines komplett gepaarten RI von $\mathrm{fr}^{3}$. Während der langen ${ }^{14} \mathrm{C}$-Markierungsperiode dieses Experimentes können Zwischenstadien des RI verwischt werden. Außerdem erwies sich die Bestimmung des Unterschiedes zwischen UV-Absorption und ${ }^{14} \mathrm{C}$-Aktivität als nicht ausreichend, um die phagenspezifischen RNA-Komponenten von denen des Wirtes genauer zu unterscheiden: Die phagenspezifische RNA wurde in der beschriebenen Versuchsanordnung in genügender Menge gebildet, um auch mit der Bestimmung der UV-Absorption erfaßt zu werden. Deshalb sollen in den folgenden Experimenten die bakterielle RNA durch
Vormarkierung und die phagenspezifische RNA durch Pulsmarkierung deutlicher voneinander getrennt werden.

\section{Vorversuche mit doppelmarkierten, nicht-infizierten Zellen}

Zellen von Stamm 58-161-22, deren stabile RNAKomponenten mit ${ }^{32} \mathrm{P}$ markiert worden waren ( $\mathrm{s}$. Methoden), erhielten für 5 min einen Puls mit ${ }^{14} \mathrm{C}$ Uracil. Anschließend wurde bei einer Probe die ${ }^{14} \mathrm{C}$ Markierung aus kurzlebigeren Komponenten wieder mit einem „chase“ (=Überschuß von nicht-radioaktivem Uracil) entfernt.

Abb. 2 zeigt einen Vergleich von Sedimentationsdiagrammen der RNA von Zellen, die mit (a) bzw. ohne (b) einem "chase“ markiert wurden. Man erkennt, daß ohne "chase“ der Einbau von ${ }^{14} \mathrm{C}$ in $23 \mathrm{~s}$ und $16 \mathrm{~s}-$ Komponenten geringer ist als mit „chase“. Gleichzeitig ist ${ }^{14} \mathrm{C}$-markiertes Material, das ohne "chase" zwischen $4 \mathrm{~s}$ und $16 \mathrm{~s}$ sedimentierte, nach dem „chase“ weitgehend verschwunden.

Die nach der an anderer Stelle ${ }^{11}$ näher beschriebenen Methoden errechneten Differenzwerte ${ }^{14} \mathrm{C}-Q_{\min }{ }^{32} \mathrm{P}$ wurden aufgetragen. Daraus resul-

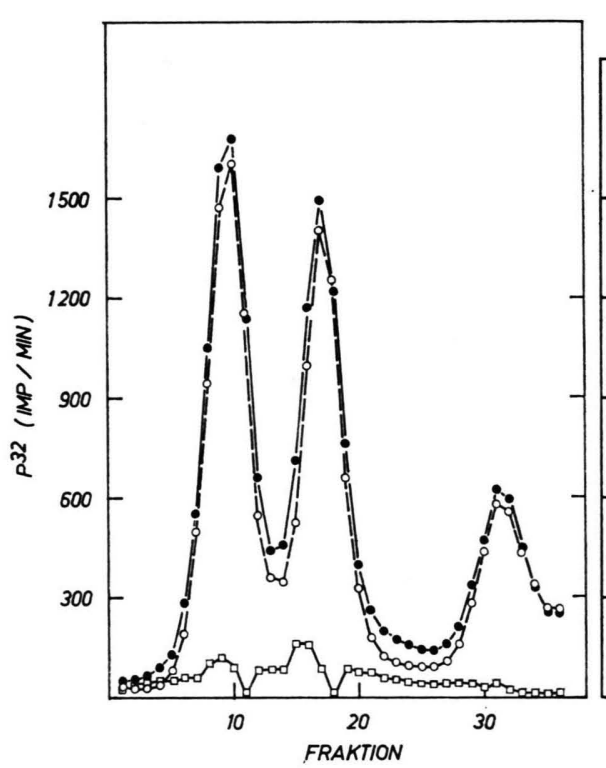

Abb. 2 a.

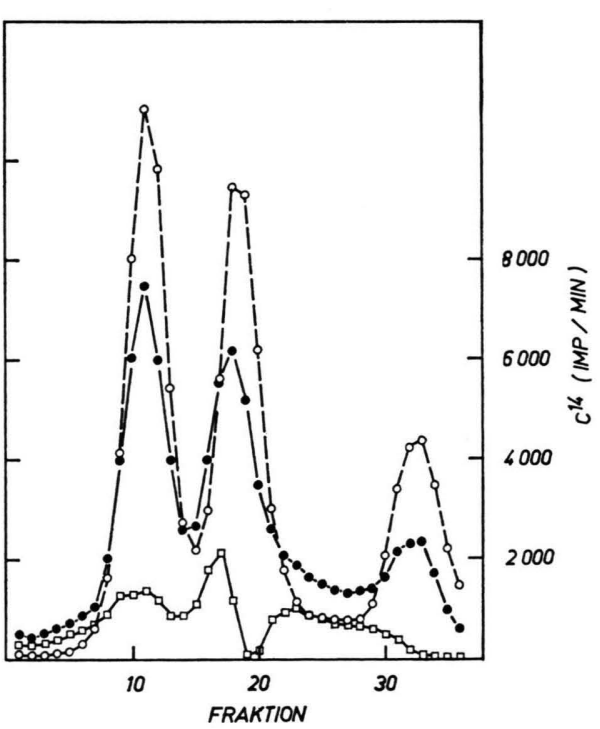

Abb. 2 b.

Abb. 2. Sedimentationsdiagramme von RNA-Extrakten von ${ }^{32} \mathrm{P}$-vormarkierten Zellen nach einem 5 -min-Puls mit ${ }^{14} \mathrm{C}$-Uracil mit (Ia) und ohne (Ib) anschließendem „chase“ mit nicht-markiertem Uracil. Die Gradienten-Sedimentation (6 Std., 35000 UPM, ca. 50, Spinco Modell L, SW 39 Rotor) erfolgte in einem 5-20-proz. Sucrosegradienten in ACE-0,1-m. NaCl-Puffer. von den ${ }^{14} \mathrm{C}$-Zählwerten wurden die normierten ${ }^{32} \mathrm{P}$-Zählwerte $\left(Q_{\min } \times{ }^{32} \mathrm{P}\right)$ abgezogen. ${ }^{32} \mathrm{P}: 0-0,{ }^{14} \mathrm{C}: \bullet-\bullet,{ }^{14} \mathrm{C}-Q_{\mathrm{min}}$ $\times{ }^{32} \mathrm{P}: \square-\square$. 
tierte eine Differenzkurve mit neuen Gipfeln. Diese Kurve erlaubte eine Abschätzung der Menge und der Sedimentations-Eigenschaften der ${ }^{14} \mathrm{C}$-pulsmarkierten RNA, die in Abweichung von den ${ }^{32} \mathrm{P}$-vormarkierten Fraktionen im Extrakt vorhanden war. Die Differenzkurven zeigen den Unterschied zwischen den beiden Markierungsmethoden noch deutlicher. Ohne „chase“ sind im Verhältnis zur ${ }^{14} \mathrm{C}$-Markierung der $4 \mathrm{~s}$-Fraktion die $23 \mathrm{~s}$ - und eine $18 \mathrm{~s}$-Fraktion stärker markiert als mit "chase“. Mit "chase“ verschwindet die Markierung der Region zwischen $4 \mathrm{~s}$ und $16 \mathrm{~s}$ weitgehend, die ohne "chase“ noch ausgeprägt ist * Für die folgenden Experimente ist also eine „chase“-Periode von 10 min genügend, um die Differenzgipfel im Verhältnis zur Bildung phagenspezifischer Gipfel ${ }^{11}$ ausreichend klein werden zu lassen.

Die Sedimentationseigenschaft der RNase-resistenten (doppelsträngigen) Phagen-RNA kann durch RNase-Behandlung alternierender Gradientenfraktionen sichtbar gemacht werden. Eine genauere $\mathrm{Ab}$ schätzung dieser RNA kann nur erfolgen, wenn der Hintergrund der zelleigenen RNase-resistenten RNA in nicht-infizierten Zellen bekannt ist. Ein Sedimentationsdiagramm einer nicht-infizierten Kontrolle, bei der alternierende Gradientenfraktionen mit RNase behandelt wurden, ist in Abb. 3 dargestellt. Ein geringer Anteil von RNase-resistentem Material

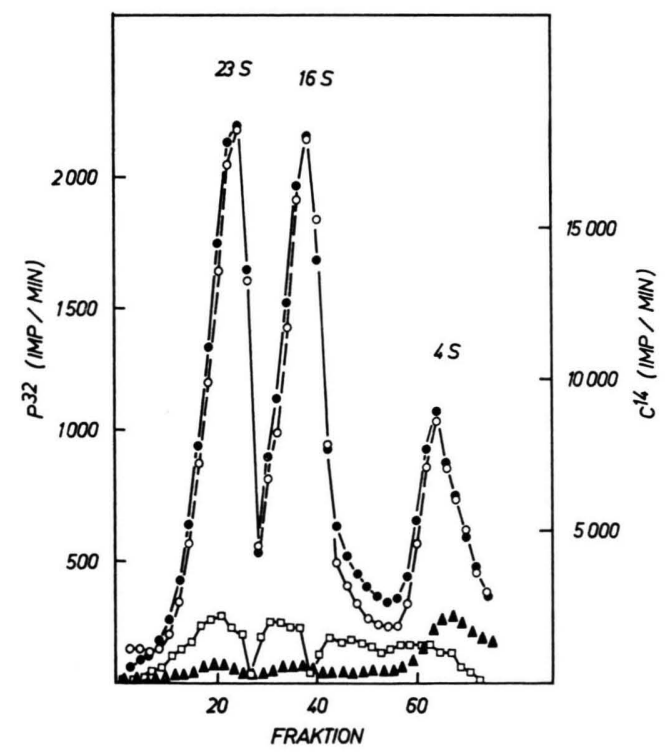

Abb. 3. Sedimentationsdiagramm eines RNA-Extraktes aus nicht-infizierten Zellen mit RNase-behandelten Fraktionen (s. Methoden). ${ }^{32} \mathrm{P}: \circ-0,{ }^{14} \mathrm{C}: \bullet-\longrightarrow ;{ }^{32} \mathrm{P}: \triangle \longrightarrow \triangle$, ${ }^{14} \mathrm{C}: \boldsymbol{\Lambda}-\boldsymbol{\Delta}$ in RNase-behandelten Fraktionen.

\section{Frauenklinik und Hebemmenschule}

\author{
der Uiversiat l. ür.cien \\ Mochen 15, Maistrabell
}

ist unter den $23 \mathrm{~s}-, 16 \mathrm{~s}$ - und $4 \mathrm{~s}-\mathrm{Gipfeln}$ zu erkennen. Das ältere, ${ }^{32} \mathrm{P}$-markierte Material zeigt dabei einen höheren Grad von RNase-Resistenz als das kurz vor der Aufarbeitung der Zellen ${ }^{14} \mathrm{C}$-pulsmarkierte Material. Es liegt nahe zu vermuten, daß diese unterschiedliche RNase-Sensitivität eine stabilere Struktur der um mehrere Generationen älteren, ${ }^{32} \mathrm{P}$-markierten RNA reflektiert.

\section{Biologische Analysen und Schema von ${ }^{14} \mathrm{C}$-Uracil- Einbauversuchen mit fr-infizierten Zellen}

Die ${ }^{14} \mathrm{C}$-Uracil-Einbauversuche mit fr-infizierten Zellen sollten an Ergebnisse der biologischen Analyse der Phagenvermehrung anknüpfen. Deshalb wurde während einiger Einbauversuche die Kapazität der Zellen, Kolonien zu bilden, die Zahl der infizierten Zellen (als SRP), die Zahl der intrazellulär vorliegenden und die der freigesetzten infektiösen Phagen bestimmt. Die Ergebnisse eines solchen Einbauexperimentes sind an einem Beispiel in Abb. 4 dargestellt. Es ergibt sich das typische Bild einer in synthetischem Medium wachsenden, fr-infizierten Bakterienkultur. Die Latenzzeit ist etwa $50 \mathrm{~min}$, die "burst size" bei 2 Stdn. etwa 500. Im unteren Teil der Abb. ist die im Methodenteil näher erläuterte Versuchsanordnung für ${ }^{14} \mathrm{C}$-Uracil-Einbauversuche schematisch dargestellt.

\section{RNA-Komponenten in infizierten Zellen während der Phagenvermehrung}

Die ${ }^{14} \mathrm{C}$-Uracil-Einbauversuche, die nach dem oben angegebenen Schema durchgeführt wurden, ergaben schließlich eine Serie von Sedimentationsdiagrammen, welche die Veränderungen der ${ }^{14} \mathrm{C}$-Uracil-Einbauaktivität der Kultur während der Phagenvermehrung wiedergeben.

In den Abbn. 5 und 6 sind Sedimentationsdiagramme dargestellt, bei denen entsprechend der in Abb. 3 dargestellten Kontrolle alternierende Fraktionen mit RNase behandelt wurden. Die ${ }^{32} \mathrm{P}-\mathrm{Zähl}$ werte sind in diesen Diagrammen nicht für den während der Zählung auftretenden radioaktiven Zerfall korrigiert worden. Dadurch ist die an anderer Stelle dargestellte Hemmung der zelleigenen RNA-Syn-

\footnotetext{
* Das Auftreten eines 18s-Gipfels ohne „chase“ und dessen weitgehendes Verschwinden nach dem "chase“ dürfte als Hinweis dafür gewertet werden, daß es sich hierbei um eine Vorläuferstufe der rRNA handelt (vgl. 1. c. ${ }^{20}$ ).
} 

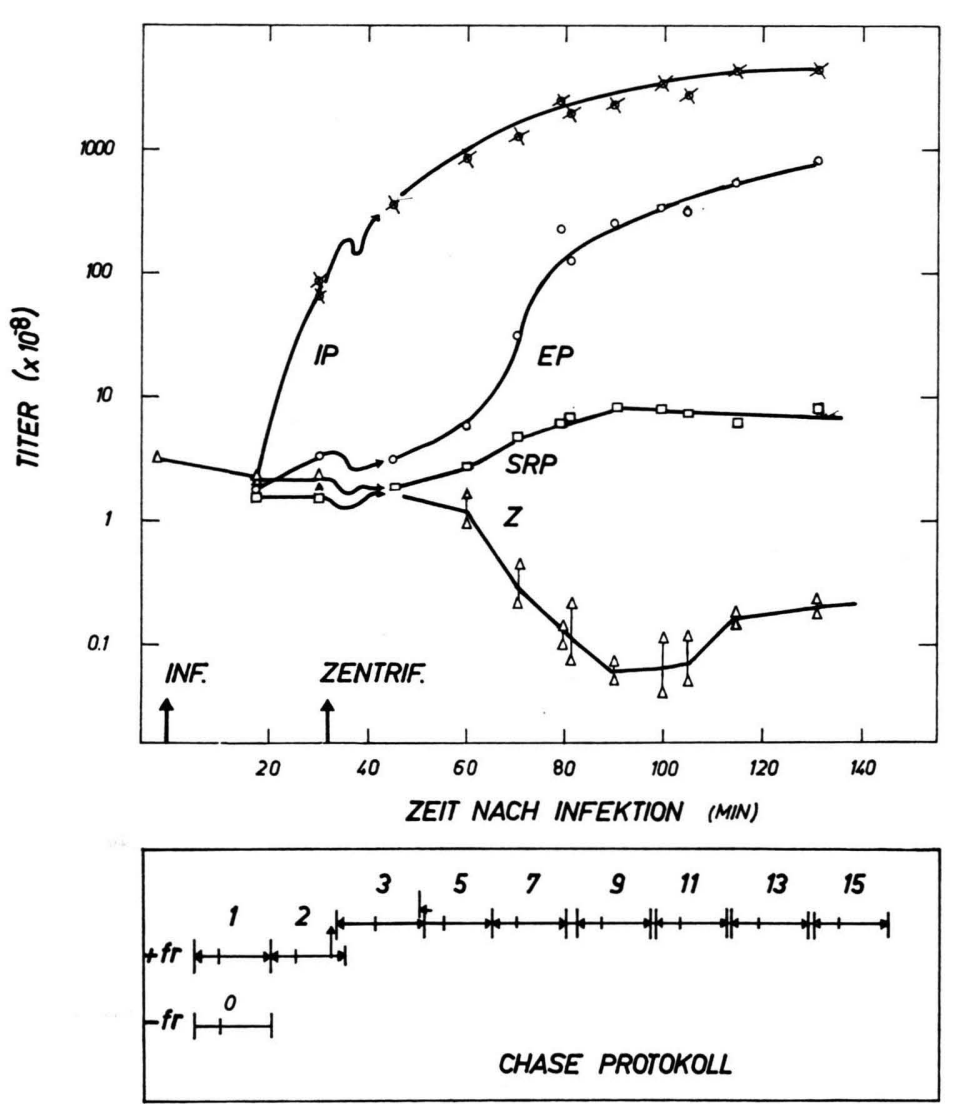

Abb. 4. Wachstumskurve für ${ }^{14} \mathrm{C}$-Uracil-Einbauversuche. Exponentiell wachsende Zellen $(58-161-22)$ wurden mit fr zur Zeit 0 infiziert. Nach 32 min wurden die Bakterien zentrifugiert, gewaschen, resuspendiert und weiterbelüftet. Der Gehalt an intrazellulären Phagen (IP $x-x$ ), extrazellulären Phagen (EP O- O ), Serum-resistenten plaquebildenden Einheiten (SRP $\square-\square$ ) und koloniebildenden Bakterienzellen $(\mathrm{Z} \triangle \longrightarrow \triangle$ ) wurde bestimmt. Im unteren Teil der Abbildung ist die Versuchsanordnung für die ${ }^{14} \mathrm{C}$-Uracil-Impulse mit „chase“ schematisch angegeben: Eine nicht-infizierte Kontrolle und verschiedene infizierte Proben wurden jeweils für 5 min mit ${ }^{14} \mathrm{C}$ Uracil, und anschließend für 10 min mit nichtmarkiertem Uracil versetzt. these ${ }^{11}$ hier weniger deutlich erkennbar. In den Diagrammen weist die ${ }^{14} \mathrm{C}$-Verteilung Verbreiterungen auf der Seite schwereren Materials in den $23 \mathrm{~s}$-, 16 s- und 4 s-Gipfeln auf. Die Zählwerte der RNasebehandelten Fraktionen lassen deutlich erkennen, daß unter der Fraktion, die anfangs bei $6 \mathrm{~s}$ auftritt (Abb. 5), ein RNase-resistenter Gipfel liegt. Diese RNase-resistente Fraktion sedimentierte mit ihrem Maximum im Verlaufe der Phagenvermehrung zunehmend schneller. Auf der Höhe der Bildung intrazellulärer nachweisbarer Phagen (ab $80 \mathrm{~min}$ ) sedimentierte sie bei $11,5 \mathrm{~s}$ (vgl. die s-Wert-Berechnungen, l. c. ${ }^{11}$ ).

Phagenspezifische ${ }^{14} \mathrm{C}$-Einbauaktivitäten wurden nach Subtraktion des korrigierten ${ }^{32} \mathrm{P}$-Hintergrundes (vgl. l. c. ${ }^{11}$ ) verdeutlicht (Abb. 7) : Neben dem bei etwa $26 \mathrm{~s}$ zu erwartenden Gipfel der Phagen$\mathrm{RNA}^{3}$ tritt auch ein im Kontrolldiagramm (Abb. 7 [o]) nur angedeuteter Gipfel bei $18 \mathrm{~s}$, und, wie zu erwarten, ein über dem RNase-resistenten Mate-

20 D. T. Dubin, J. molecular Biol. 8, 749 [1964]. rial gelegener Gipfel mit zunehmenden $s$-Werten auf. Die Art dieser Analyse läßt offen, ob es sich bei dem 18 s-Material um zelleigene RNA, Phagen-RNA oder einer Mischung beider handelt. Es ist möglich, daß es sich dabei um eine Vorläuferfraktion der rRNA handelt (l. c. ${ }^{20}$ ). Diese Fraktion wurde oben näher beschrieben (vgl. Abb. 2) ; sie tritt in diesem Stamm verstärkt in Abwesenheit von Methionin auf ${ }^{12}$.

In einigen Diagrammserien wurden die $s$-Werte des Maximums der veränderlichen RNase-resistenten Komponente nach MARTiN und Ames ${ }^{21}$ abgeschätzt und mit den $s$-Werten der ersten beiden Differenzgipfel verglichen. Während dabei gute Ubereinstimmung für $26 \mathrm{~s}$ - und $18 \mathrm{~s}$-Fraktionen gefunden wurde, nahm die Fraktion, die RNase-resistentes Material enthielt, im Verlaufe der Phagenvermehrung von $6 \mathrm{~s}$ bis 11,5 $\mathrm{s} \mathrm{zu}{ }^{11}$; gleichzeitig verbreiterten sich die resistenten Fraktionen in den Bereich höherer $s$-Werte, so daß sie in späten Vermehrungsphasen bis über die $18 \mathrm{~s}$-Fraktion hinaus reichten (Abb. 7).

21 R. G. Martin u. B. N. Ames, J. biol. Chemistry 236, 1372 [1961]. 


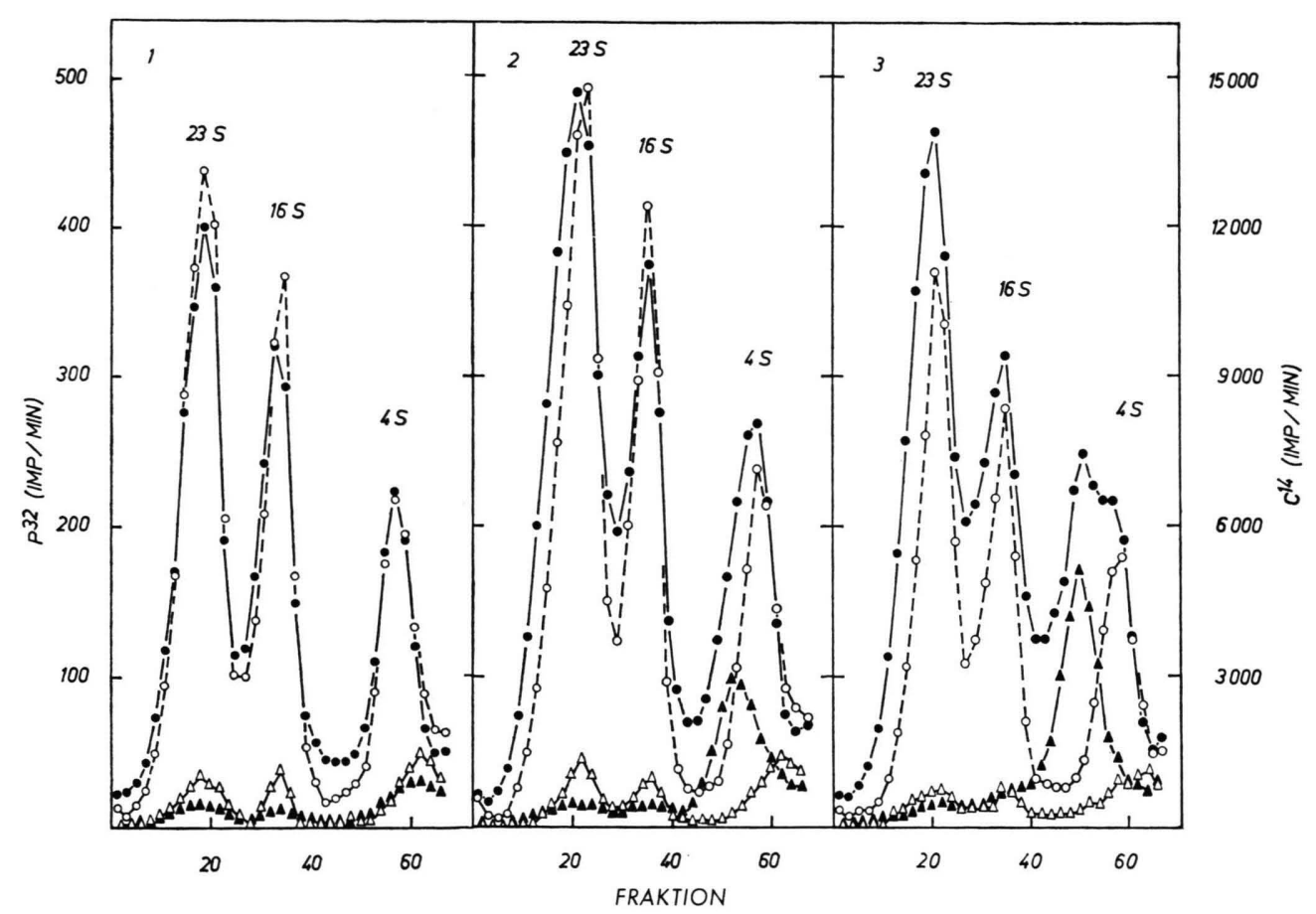

Abb. 5.

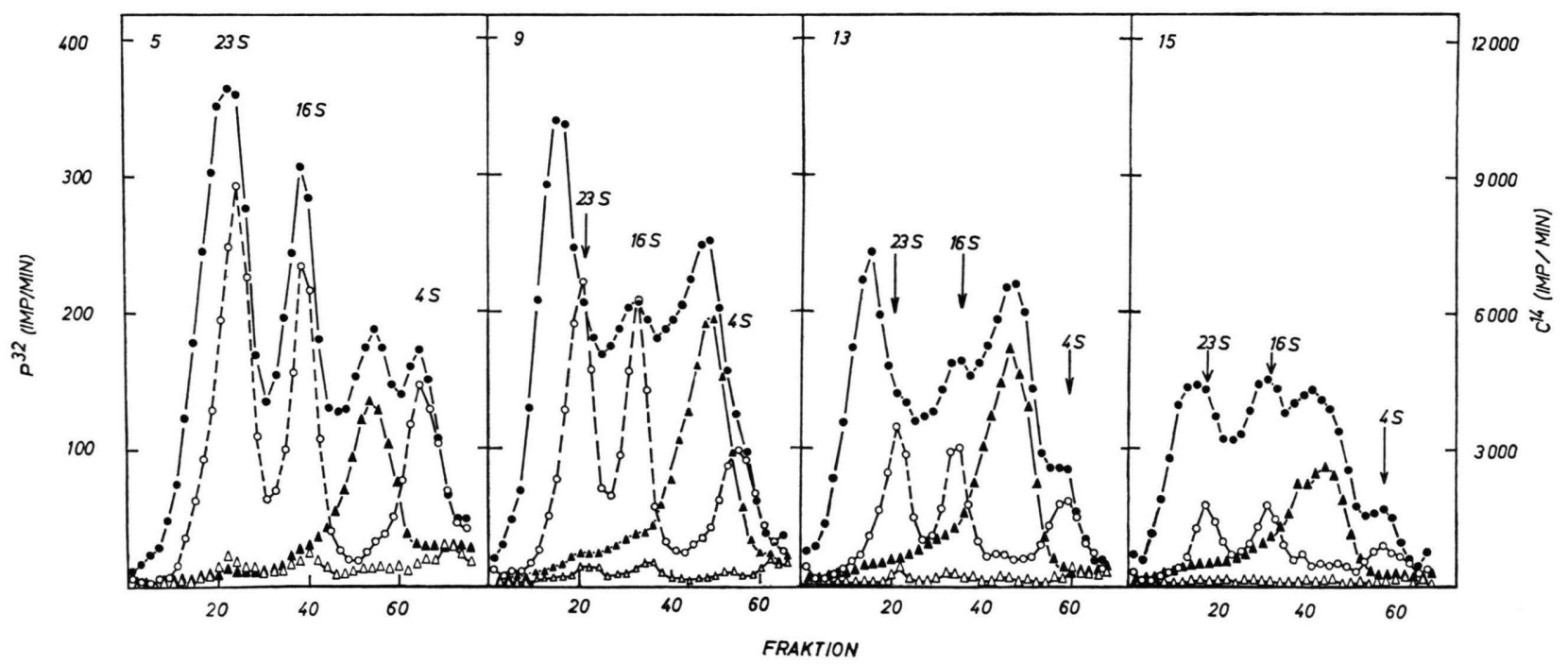

Abb. 6.

Abbn. 5 u. 6. Sedimentationsdiagramme infizierter Zellen (unkorrigierte Zählwerte). Alternierende Gradientenfraktionen wurden mit RNase behandelt (s. Methoden). Probennumerierung s. Abb. 4.

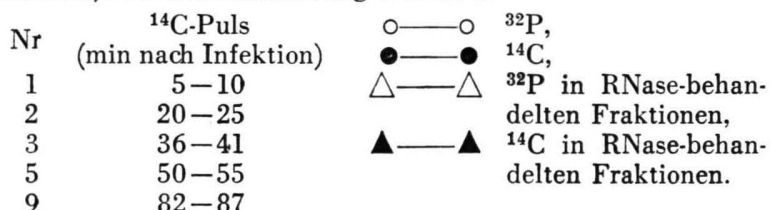

$$
\begin{aligned}
& 13 \quad 114-119 \\
& 15 \quad 130-135
\end{aligned}
$$




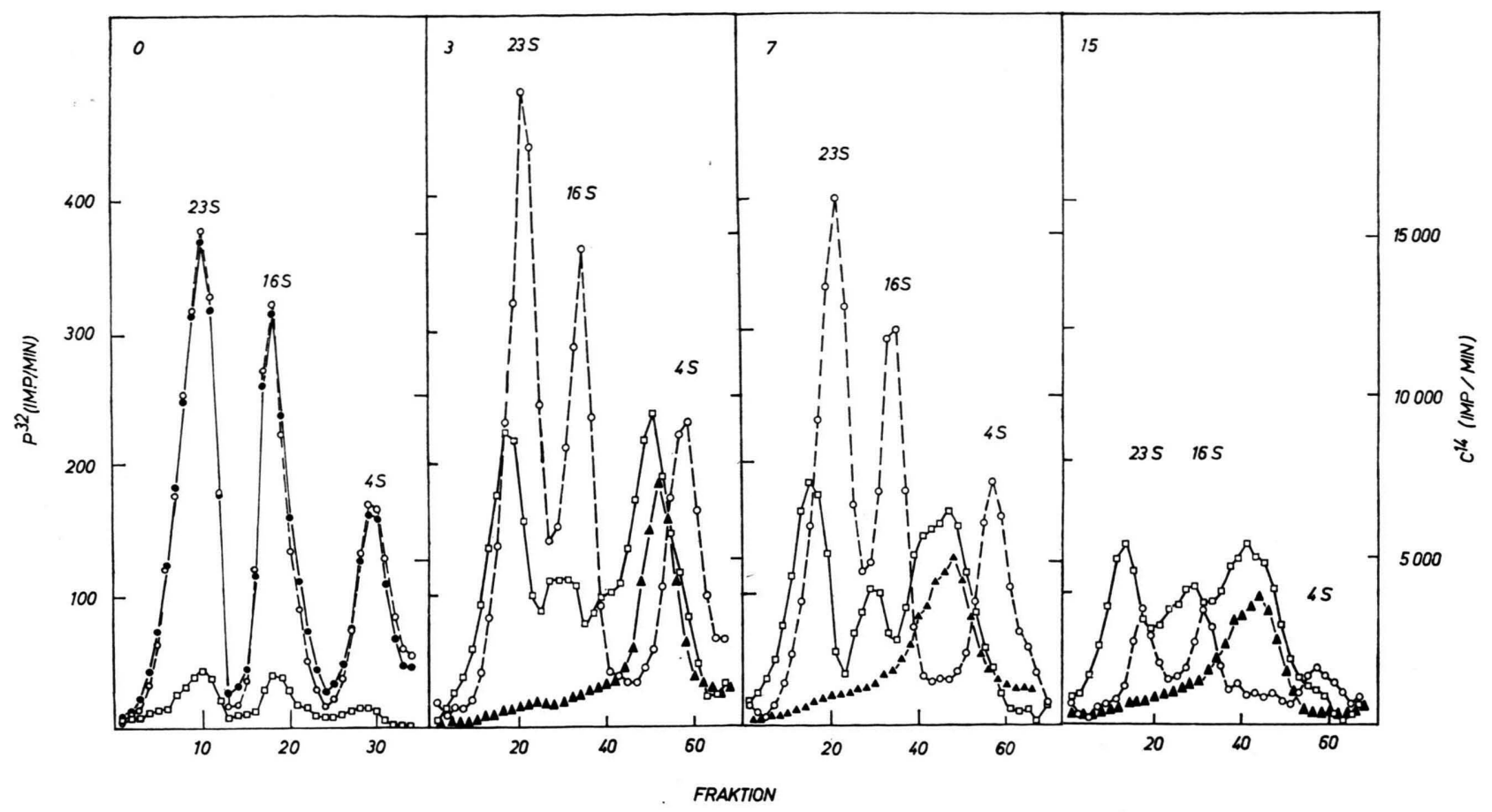

Abb. 7. Sedimentationsdiagramme infizierter Zellen: Darstellung der spezifisch nach der Infektion gebildeten Gipfel (durch Subtraktion der normierten ${ }^{32} \mathrm{P}$. von den ${ }^{14} \mathrm{C}$-Zählwerten, s. Text). Zeichenerklärung und Numerierung s. Abbn. $5 \mathrm{u}$. 6 , ${ }^{14} \mathrm{C}-Q_{\min } \times{ }^{32} \mathrm{P}$ :

\section{Sedimentationsdiagramme nach RNase-Behand- lung der RNA infizierter Zellen}

Abweichend von den Ergebnissen anderer Autoren $2,3,6,8,9$ wurden in den vorliegenden Experimenten während der Phagenvermehrung zunehmende $s$-Werte für eine langsam sedimentierende RNaseresistente Fraktion gefunden. Es schien deshalb angezeigt, die Größe des „core“-Materials ${ }^{6,9}$ zu bestimmen. Dazu wurden RNA-Extrakte fr-infizierter Zellen vor der Gradientensedimentation mit verschiedenen RNase-Mengen behandelt; der Extrakt einer nicht-infizierten Kontrolle wurde mit 0,33 $\mu \mathrm{g}$ RNase/ml inkubiert. Nach der RNase-Bebrütung wurde ${ }^{32} \mathrm{P}$-markierte Zell-RNA zugefügt; die Extrakte wurden sofort im Sucrosegradienten sedimentiert. Das Diagramm einer Probe aus infizierten Zellen (vgl. Abb. 6 [13]) ist in Abb. 8 dargestellt. Als Referenzmarkierung wurde das Sedimentationsdiagramm einer gleichzeitig zentrifugierten ${ }^{32} \mathrm{P}$-Bakterien-RNA eingezeichnet. Die Abb. läßt erkennen, $\mathrm{da} ß$ statt der vorher bei $11,5 \mathrm{~s}$ sedimentierenden RNase-resistenten Fraktion (Abb. 6) nunmehr eine Fraktion bei etwa $7,5 \mathrm{~s}$ sedimentiert, die noch einen

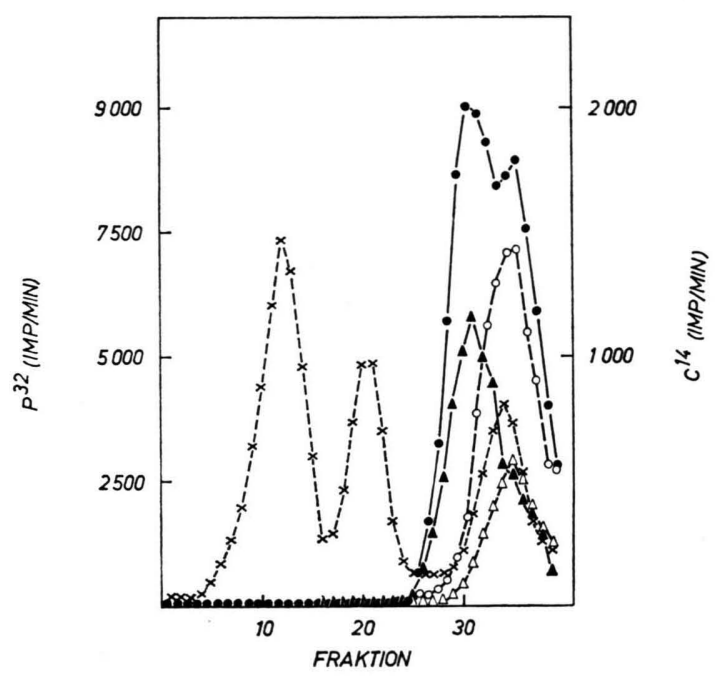

Abb. 8. Sedimentationsdiagramm eines RNase-vorbehandelten Extraktes. Die Hälfte des RNA-Extraktes Nr. 13 (vgl. Abb. 4) wurde mit $0,33 \mu \mathrm{g}$ RNase/ml für 30 min bei $37^{\circ}$ behandelt. Eine doppelte Menge ${ }^{32}$ P-Bakterien-RNA wurde zugefügt. Das Gemisch wurde sofort im Sucrosegradienten sedimentiert. Gleichzeitig wurde ${ }^{32} \mathrm{P}$-Bakterien-RNA als Kontrolle sedimentiert. Anschließend wurden alternierende Fraktionen mit RNase behandelt (s. Methoden). Zeichenerklärung s. Abbn. 5 und $6 . x-x^{32} \mathrm{P}$-Kontrolle. 
Rest von RNase-Sensitivität zeigt. Die RNase-behandelte Kontrolle (aus nicht-infizierten Zellen) wurde dagegen ähnlich der ${ }^{32} \mathrm{P}$-markierten Zell-RNA zu niedermolekularem Material abgebaut, das langsamer als mit $4 \mathrm{~s}$ sedimentierte. Mit 10 -fach geringeren und mit 10-fach höheren Enzymkonzentrationen wurden für die RNase-resistente Phagen-RNA jeweils Fraktionen mit $s$-Werten um 7,5 s erhalten.

\section{Abschätzung der ${ }^{14} C$-Uracil-Einbauaktivitäten}

Die Eingabemenge der ${ }^{32} \mathrm{P}$-vormarkierten Zellen sowie deren Aufarbeitung und Fraktionierung war bei allen Proben des in den Abbn. 4-7 dargestellten Experimentes gleich. Deshalb ist die Summe der ${ }^{32} \mathrm{P}$-Impulse pro Sedimentationsdiagramm ein $\mathrm{Ma} \beta$ für die Menge der zum Ende der jeweiligen ${ }^{14} \mathrm{C}$ Markierungsperiode noch vorhandenen intakten Zellen des Infektionsgemisches. Gleichzeitig ist dies auch ein Maß für die jeweilige Gesamtzellmenge, solange die Zellen der infizierten Kultur sich nicht signifikant vermehren. Die Zahl der koloniebildenden Bakterien (Abb.4) zeigt an, daß dieser $\mathrm{Zu}$ wachs erst etwa $1 \frac{1}{2}$ Stde. nach der Infektion ins Gewicht zu fallen beginnt. Das bedeutet, daß dann die mit Hilfe der ${ }^{32} \mathrm{P}$-Markierung erhaltenen Abschätzwerte der Gesamtzellmenge entsprechend (in diesem Falle $<10 \%$ ) zu niedrig sein würden.

In Abb. 9 sind die Summen der ${ }^{32}$-P-Impulse, die aus den Sedimentationsdiagrammen des in den Abbn. 4-7 dargestellten Experimentes erhalten wurden, in Abhängigkeit von der Zeit als Relativ-

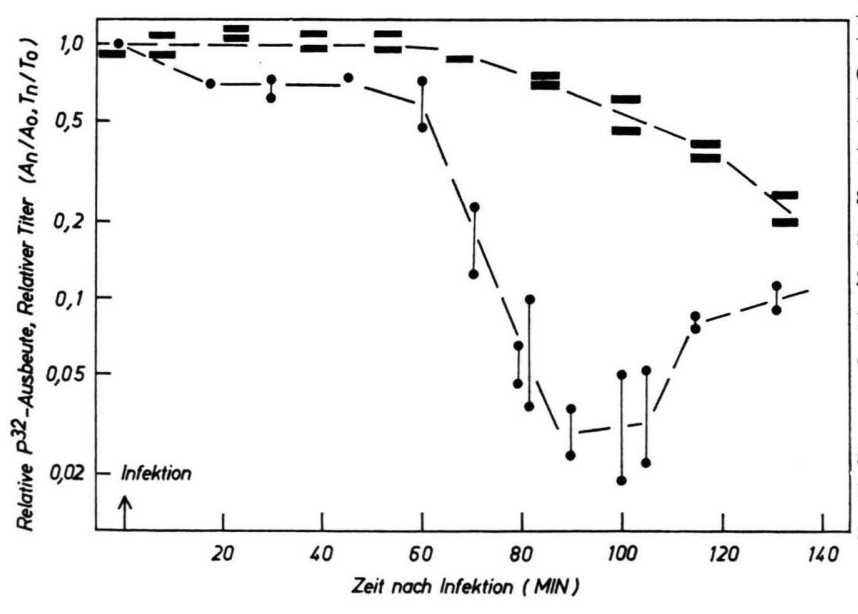

Abb. 9. Relative Summen der ${ }^{32} \mathrm{P}-Z$ Zählwerte pro Sedimentationsdiagramm (s. Abbn. 5-7) des in Abb. 4 dargestellten Experimentes. (घ- $)$; rel. Titer der koloniebildenden Bakterien: $\longrightarrow$. werte eingetragen worden. Als Referenzkurve wurde die relative Zahl der koloniebildenden Bakterien (vgl. Abb. 4) eingezeichnet. Es sind jeweils zwei Diagramme und zwei Bakterienbestimmungen ausgewertet und eingetragen worden. Die ${ }^{32} \mathrm{P}$-Werte zeigen befriedigende Gleichmäßigkeit. Der Unterschied zwischen den langsam abnehmenden ${ }^{32} \mathrm{P}$.Werten und der schneller absinkenden Zahl der koloniebildenden Bakterien dürfte durch Abtötung oder Lyse nach der Probenentnahme erklärbar sein.

Somit sind die Summen der ${ }^{32}$ P-Impulse ein brauchbares $\mathrm{Ma} ß$ für die jeweils noch vorhandenen Zellmengen des Infektionsgemisches; entsprechend ergeben die Summen der ${ }^{14} \mathrm{C}$-Impulse ein $\mathrm{Ma} \beta$ für die jeweilige ${ }^{14} \mathrm{C}$-Uracil-Einbauaktivität der Probe. Aus den Summen der ${ }^{32}$ P-Impulse läßt sich für jede Probe ein Korrekturfaktor ermitteln, mit dem diese auf die Kontrolle normiert werden kann. Multipliziert man die Summen der ${ }^{14} \mathrm{C}$-Impulse mit dem jeweiligen Normierungsfaktor, erhält man ein $\mathrm{Ma}$ für den ${ }^{14} \mathrm{C}$-Uracil-Einbau pro Zelleinheit. Dabei wird für Proben, die später als $1 \frac{1}{2}$ Stde. nach der Infektion entnommen wurden, nur ein geringer Fehler auftreten, da die inzwischen wachsenden Zellen bei dieser Abschätzung nicht berücksichtigt werden, wie oben bereits ausgeführt wurde.

So wurden die ${ }^{14} \mathrm{C}$-Impulse der $26 \mathrm{~s}$-, $18 \mathrm{~s}$ - und 6 - 11,5 s-Fraktionen der Sedimentationsdiagramme addiert und korrigiert. Von diesen Werten wurden dann die entsprechenden Summen der Kontrollkultur (z.B. Abb. 7 [o]) subtrahiert. Damit erhält man ein Maß für die nach der Infektion neugebildeten Anteile dieser Fraktionen pro Zelleinheit. Bei der Errechnung der RNase-resistenten Fraktion wurde von der Summe der RNase-resistenten ${ }^{14} \mathrm{C}$ Impulse die Sume der RNase-resistenten Impulse des Kontrolldiagramms (z. B. Abb. 3) subtrahiert. Diese Fraktion ist also etwas größer als die RNaseteilresistente 6-11,5 s-Fraktion (Abbn. 5-7) : In späten Vermehrungsstadien reicht die RNase-resistente Fraktion bis weit über 11,5 s hinaus. Ein etwa zugehöriger, phagenspezifischer, RNase-teilresistenter Anteil kann aber mit den hier benutzten Methoden nicht eindeutig abgeschätzt werden.

Die ermittelten Werte sind in Abb. 10 aufgetragen worden. Als Referenzkurve ist die Zahl der intrazellulär nachweisbaren Phagen (vgl. Abb. 4) entsprechend korrigiert * eingetragen worden. Ein Ver-

* Die Art dieser Auftragung verdeutlicht, daß ein Plateau der Bildung intrazellulärer infektiöser Partikel ab etwa 80 min nur durch die Zell-Lyse vorgetäuscht wird (Abb. 4); die noch intakten Zellen produzieren Phagen nach diesem Zeitpunkt mit derselben Rate wie vorher. 


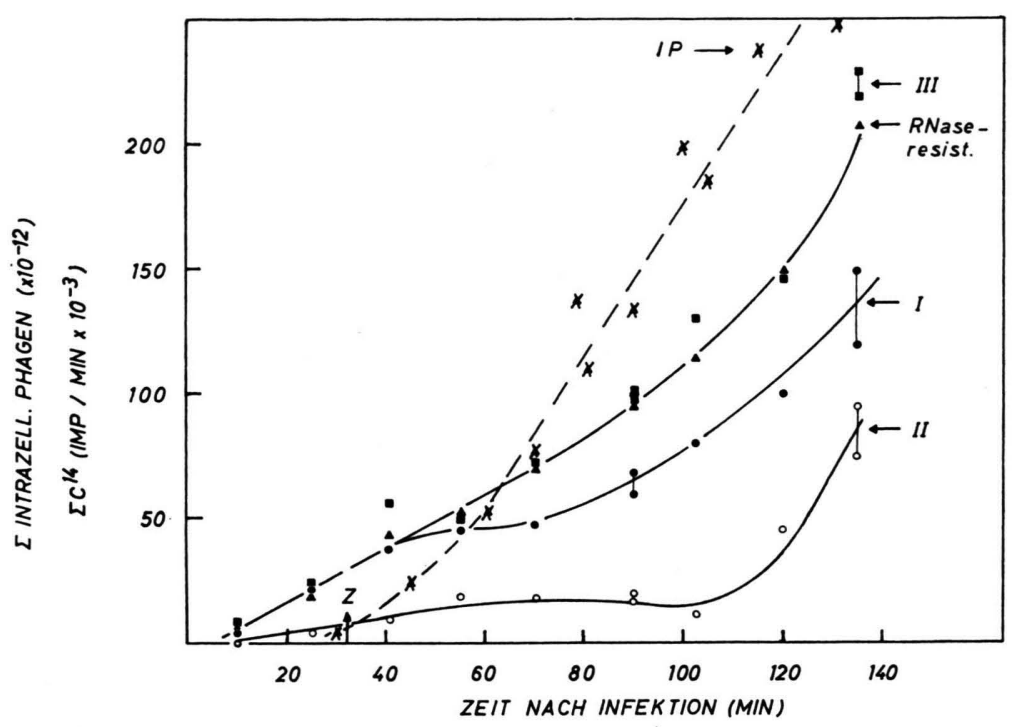

Abb. 10. Zunahme der intrazellulären Phagen (IP), 26s-RNA (I), 18s-RNA (II), 6-11,5s-RNA (III) und RNase-resistenter RNA in Sedimentationsdiagrammen (s. Abbn. 5-7) nach der Infektion. gleich der ${ }^{14} \mathrm{C}$-Einbauaktivitäten in RNase-resistentes Material und in die $26 \mathrm{~s}$-Phagen-RNA läßt erkennen, $\mathrm{da} ß$ letztere (besonders ab $30-40 \mathrm{~min}$ ) kleiner ist. Das kann damit erklärt werden, daß ein beträchtlicher Anteil der von dem RI abgelösten Phagenstränge während der Markierungsperiode wieder in den Replikationszyklus eingeht (s. u.). In Experimenten, in denen andere Wirtszellen und Phagenpräparate benutzt wurden, und bei denen der Anstieg des $s$-Wertes der RNase-resistenten Fraktion relativ schneller und zu etwas höheren $s$-Werten verlief, war auch das Verhältnis von $26 \mathrm{~s}-\mathrm{RNA}$ zu RNaseresistenter RNA größer.

Während die 18 s-Fraktion bis etwa 110 min konstant blieb, nahm sie später zu. Da um diese Zeit auch die RNase-resistente Komponente sich in schwerere Bereiche stark verbreiterte, ist anzunehmen, daß während dieser späten Vermehrungsperiode die 18 s-Komponente mit RNase-teilresistentem Material überlagert ist, was durch diese Analyse nicht unterschieden werden kann. Hinzu kommt, daß von dieser Zeit an die ${ }^{32} \mathrm{P}$-Normierung zu leicht erhöhten ${ }^{14} \mathrm{C}$-Werten führen kann (s. o.).

\section{Diskussion}

A. Die Befunde dieser Arbeit ergaben, daß die RNA fr-infizierter Zellen charakteristische Veränderungen zeigt:

\footnotetext{
22 P. Knolle, unveröffentlichte Ergebnisse.
}

Eine Fraktion, die RNase-resistene RNA enthielt, konnte dargestellt werden, deren Gipfel im Sucrosegradienten anfangs bei $6 \mathrm{~s}$ sedimentierte. Diese Fraktion wurde im Verlaufe der Phagenvermehrung größer. Gleichzeitig verschob sich deren Maximum bis $11,5 \mathrm{~s}$.

Diese Fraktion wird unter normalen Infektionsbedingungen qualitativ wirtsunabhängig gebildet (vgl. auch l. c. ${ }^{12}$ ), sie ist kein Artefakt der Anzüchtung des Wirtes oder dessen Aufarbeitung: Wuchsen infizierte Zellen in Vollmedium (YT) oder wurden sie nach Methoden aufgearbeitet, mit denen in Extrakten MS2-infizierter Zellen 14-16 s-RI dargestellt werden konnte, wurden stets Ergebnisse erhalten, die den hier mitgeteilten Befunden entsprachen ${ }^{22}$. Es ist auch unwahrscheinlich, daß diese „leichte“ RNA während der Aufarbeitung durch Scherkräfte entsteht (vgl. l. c. ${ }^{3}$ ) oder daß sie ein Abbauprodukt der „ribosomalen“ Ribonuklease ist: Die f2-Mutante sus-3 produziert ähnliches $7 \mathrm{~s}$-Material auch in Stämmen, denen dieses Enzym fehlt ${ }^{23}$.

Diese langsam sedimentierende Fraktion scheint im Verlaufe der Phagenvermehrung in größeren Mengen gebildet zu werden, so daß sie in späten Vermehrungsstadien des Phagen auch als Verbreiterung des $O D$-Profils der 4-10 s-Region im Sedimentationsdiagramm des RNA-Extraktes sichtbar wird.

23 N. D. ZINDER, persönl. Mitteilung. 
B. Diese Befunde unterscheiden sich von denen, die mit anderen RNA-Phagen erhalten wurden:

1. Da die zelleigene RNA-Synthese nach der Infektion durch RNA-Phagen nur geringfügig gehemmt wird (vgl. l. c. ${ }^{6,11}$, s. aber auch l. c. ${ }^{24}$ ), wurde die Bildung phagenspezifischer RNA-Fraktionen meist in Zellen untersucht, deren eigene RNASynthese gehemmt war. Der Verbleib infizierender (markierter) Phagen-RNA konnte jedoch auch in ungehemmten Zellen untersucht werden.

Dabei wurde in RNA-Extrakten R17-infizierter Zellen die parentale RNA in einer RNase-resistenten Fraktion gefunden, die bei etwa $14 \mathrm{~s}$ sedimentierte und bis weit in den Bereich höherer $s$-Werte reichte ${ }^{8}$. Entsprechend verhielt sich parentale f2-RNA, die in einer breiten Bande mit Gipfeln bei $14 \mathrm{~s}$ und bei 18 s sedimentierte ${ }^{7}$.

2. In RNA-Extrakten UV-bestrahlter Zellen wurden neben der $27 \mathrm{~s}$-Phagen-RNA zwei RNase-resistente Fraktionen beobachtet, von den die eine bei $15 \mathrm{~s}$ und die andere bei $6 \mathrm{~s}$ sedimentierte. In diesen Fraktionen fand sich sowohl parentale Phagen-RNA als auch Einbauaktivität (d. h. neu gebildete, phagenspezifische RNA, vgl. l.c. ${ }^{8}$ ). Nach Vergiftung MS2-infizierter Protoplasten mit Actinomycin D fand sich ähnlich bei $15 \mathrm{~s}$ und bei $6 \mathrm{~s}$ RNase-resistente, neugebildete Phagen-RNA ${ }^{9}$.

3. In seinen anfänglichen Sedimentations-Eigenschaften entspräche das fr-spezifische, RNase-resistente Material einer $7 \mathrm{~s}$-Fraktion, die mit $\mathrm{f} 2$ bei $43^{\circ}$, mit amber-Hüllproteinmutanten von $\mathrm{f} 2^{7}$ und mit der MS2-Mutante am-9 ${ }^{25}$ in infizierten Zellen gebildet wird.

Dabei wird angenommen, daß die Anhäufung der 7 s-Fraktion eine Folge der veränderten Proteinsynthese bei $43^{\circ}$ bzw. der Unterbrechung der Hüllproteinsynthese im Falle der am-Mutanten ist.

Jedoch unterscheidet sich fr von am-Mutanten: In $\mathrm{su}^{-}-$Stämmen wird eine $\mathrm{MS}^{+}$entsprechende Phagenausbeute erhalten ${ }^{22}$, und sus- 3 kann durch eine frPlaquemutante restauriert werden ${ }^{26}$.

C. Entsprechend den Vorstellungen von WeIssmann et al. ${ }^{1,27}$ und von Fenwick et al. ${ }^{6}$ sollten in fr-infizierten Zellen 2 Klassen von RNase-(teil-) resistenten RNA-Fraktionen zu finden sein:

24 D. B. Ellis u. W. Paranchych, J. cellular comparat. Physiol. 62, 207 [1963].

25 C. Weissmann, persönliche Mitteilung.

${ }^{26}$ P. Knolle, Z. Vererbungslehre 98, 278 [1966].

27 S. Ochoa, C. Weissmann, P. Borst, R. H. Burdon u. M. A. Billeter, Federat. Proc. 23, 1285 [1964].
1. Die infizierende Phagen-RNA hat zunächst die Funktion einer mRNA: Sie wird sofort nach der Infektion an Ribosomen gefunden ${ }^{3,8}$, *. Dabei dürfte u. a. Enzym I (und II?) gebildet werden. Enzym I benutzt dann einen Teil der parentalen RNA als Matrize zur Bildung eines komplementären Stranges (Negativkopie, ,- “-Strang), wodurch die parentale RNA RNase-resistent erhalten wird ${ }^{1,2,8}$.

Dieses erste, von Enzym I katalysierte Intermediärprodukt, soll als RI-I bezeichnet werden. Die Bildung dieses Produktes ist bisher weniger untersucht worden bzw. es wird bezweifelt, ob ein solches Produkt für die Phagen-RNA-Replikation erforderlich ist (s. l. c. ${ }^{28}$ ).

2. Nachdem die Negativkopie komplett ist, geht das Produkt (mittels Enzym II?) in eine neue Form über, die als RI-II bezeichnet werden soll: Durch asymmetrische Replikation wird neue Phagen-RNA gebildet, während sich der vorher am „- “-Strang gebundene "+ "-Strang aus dem Matrizenverband löst ${ }^{6,27}$. Bei MS2 wird dann ein kleiner Teil der neusynthetisierten "+ "-Stränge wiederum durch Enzym I in Doppelstrang überführt ${ }^{25}$. Material, das in RI-II eingebaut wird, ist nach Dodecylsulfat-Phenolbehandlung gegen die Einwirkung von gereinigter Pankreas-RNase weitgehend beständig ${ }^{29}$. Die RNase-teilresistente Fraktion des RI-II setzt sich also aus doppelsträngigem „core“ und daranhängenden, teilweise abgespreizten Phagen-RNA-Strängen zusammen. Je nach Zahl und Länge der abgespreizten Stränge würden unterschiedliche $s$-Werte des Komplexes zu erwarten sein.

Durch die milde RNase-Behandlung können die freien Stränge bis an das „core“ des RI-II abgebaut werden. Eine als „core“ interpretierte Fraktion sedimentierte nach Behandlung des RI-II mit 0,001 $\mu \mathrm{g}$ $\mathrm{RNase} / \mathrm{ml}$ bei $12 \mathrm{~s}$; durch höhere RNase-Konzentrationen konnte es weiter abgebaut werden; nach Behandlung mit $5 \mu \mathrm{g}$ RNase/ml sedimentierte es bei etwa $8 \mathrm{~s}^{6}$. (In anderen Versuchen wurde nach Behandlung mit $0,1 \mu \mathrm{g} \mathrm{RNase} / \mathrm{ml}$ eine Fraktion bei $12 \mathrm{~s}$ beobachtet ${ }^{8}$; nach Verdauung eines Extraktes aus MS2-infizierten Zellen mit $0,5 \mu \mathrm{g}$ RNase $/ \mathrm{ml}$ sedimentierte eine Fraktion bei $16-18 \mathrm{~s}^{2}$ oder $12-13 \mathrm{~s}^{9}$; nach Behandlung mit $0,1 \mu \mathrm{g}$ RNase/ml, einer Konzentration, die ausreichte, alle Einzelstrang-RNA abzubauen, und bei der der Abbau von Doppelstrangmaterial minimal war, wurde $12 \mathrm{~s}$-Material erhalten ${ }^{9}$.)

* Diese Anheftung mag für die Invasion der Phagen-RNA von Bedeutung sein, die in Gegenwart von $\mathrm{CM}$ verlangsamt ist ${ }^{17}$.

28 S. Spiegelman u. I. Haruna, J. gen. Physiol. 49, 263 [1966].

29 P. Borst u. C. Weissmann, Proc. nat. Acad. Sci. USA 54. 982 [1965]. 
Im vorliegenden Falle würden der RI-II jene Fraktionen entsprechen, die mit $s$-Werten $>13$ sedimentierten und auch nach dem "chase“ noch als markiert darstellbar waren. Nachdem ein RNA-Extrakt fr-infizierter Zellen (114-129 min nach der Infektion markiert) mit $0,33 \mu \mathrm{g}$ RNase/ml behandelt wurde, sedimentierte eine RNase-resistente Fraktion bei 7,5 s. Mit anderen Enzymkonzentrationen (z. B. $0,033 \mu \mathrm{g} / \mathrm{ml}$ ) konnten kaum Veränderungen in den $s$-Werten der resistenten Fraktion beobachtet werden; den Enzymkonzentrationen entsprechend waren lediglich jeweils die Gipfelausbeuten verändert. Wenn auch der größere Teil der ${ }^{14} \mathrm{C}$-Markierung des 7,5 s-Gipfels den doppelsträngigen Teilstücken des RI-I entsprechen sollte (s. u.), so ist doch unerwartet, daß die Markierung des RI-II keinen 2. Gipfel bei etwa $13 \mathrm{~s}$ hinterließ. Vermutlich reichte selbst die niedrige Enzymkonzentration aus, Brüche im sog. "core“ zu verursachen.

Die „leichte“ RNase-resistente Fraktion, die in Sedimentationsdiagrammen darstellbar war, wenn Gradientenfraktionen nach der Sedimentation Enzym-behandelt wurden, zeigt die Merkmale von verkürztem (oder starrem) RI-I bzw. von nicht-replizierenden RI-II Anteilen:

a) $\mathrm{Die}{ }^{14} \mathrm{C}$-Uracil-Markierung dieser RNAFraktion war nach Sedimentation weitgehend RNase- beständig, während die RNase-Behandlung vor der Sedimentation die erwarteten, bei niedrigen $s$-Werten sedimentierenden Teilstücke ergibt.

b) Das in "leichte“ RNA-Fraktionen eingebaute ${ }^{14} \mathrm{C}$-Uracil ist auch nach einem 10-min-,,chase“ noch darin anzutreffen; es zeigt keinen der $16 \mathrm{~s}$-RI (RIII) von MS2 entsprechenden "turnover" 22 .

c) Nach einem Puls mit ${ }^{14} \mathrm{C}$-Uracil sedimentiert die markierte Fraktion langsamer als nach einem darauffolgenden „,chase“ 22 .

$\mathrm{Ob}$ die RNase-resistenten RNA-Fraktionen auch schon in vivo vorliegen, und ob ihnen (insbesondere den langsam sedimentierenden Anteilen) eine Funktion bei der RNA-Replikation oder der Transkription zukommt, kann erst durch weitere Untersuchungen entschieden werden.

Die Arbeit wurde durch Sachbeihilfen der Deutschen Forschungsgemeinschaft an Prof. F. Kaudewitz und an den Autor unterstützt. Das Bu ndesministerium für Wissenschaftliche Forschung und die Max-Planck-Gesell$\mathrm{sch}$ a $\mathrm{t}$ förderten die Arbeit durch eine Beihilfe und ein Stipendium. Herrn Dr. G. Stent sei für die Überlassung von Stamm 58-161, Herrn Dr. H. HoffmanNBerling für fr und Stamm 3300, Herrn Dr. A. Gierer, Dr. C. Weissmann und Dr. H. G. Zachau sei für kritische Diskussionen, Frl. H. Lemme, H. Koehler und U. JAUKER für sorgfältige technische Assistenz während verschiedener Phasen der Arbeit gedankt. 